\title{
Retrospective self-reported weight changes during childhood and adolescence are not good predictors of metabolic syndrome risk factors in Mexican young adults
}

\author{
Flávia C. D. Andrade ${ }^{1^{*}}$, Michelle Jiménez ${ }^{1}$, Marcela Raffaelli², Margarita Teran-García ${ }^{3}$, \\ Celia Aradillas-García ${ }^{4}$ \\ ${ }^{1}$ Department of Kinesiology and Community Health, University of Illinois at Urbana-Champaign, Urbana, USA; \\ *Corresponding Author: fandrade@illinois.edu \\ ${ }^{2}$ Department of Human and Community Development, University of Illinois at Urbana-Champaign, Urbana, USA \\ ${ }^{3}$ Department of Food Sciences and Human Nutrition, University of Illinois at Urbana-Champaign, Urbana, USA \\ ${ }^{4}$ Faculty of Medicine, University Autonomous of San Luis Potosí, San Luis Potosí, Mexico
}

Received 24 September 2013; revised 18 October 2013; accepted 27 October 2013

Copyright (C) 2013 Flávia C. D. Andrade et al. This is an open access article distributed under the Creative Commons Attribution License, which permits unrestricted use, distribution, and reproduction in any medium, provided the original work is properly cited.

\begin{abstract}
The purpose of the study was to examine whether retrospective self-reported weight changes during childhood and adolescence were associated with metabolic syndrome (MetS) risk factors in Mexican young adults. Mexican college applicants to the Universidad Autónoma de San Luis Potosí, Mexico, 18 to 25 years old $(n=4187)$ who had applied for the 2009 academic year were included in the study. Participants underwent a health screening-anthropometrics and blood drawn-and completed a questionnaire. Five major weight change categories were defined based on self-reported weight during childhood and adolescence: consistently normal, consistently underweight, consistently overweight/ obese, weight gain, and weight loss. Most participants self-reported being normal weight during childhood (58.7\%) and adolescence (58.3\%). Only a small proportion reported being overweight or obese during childhood $(10.1 \%)$ or adolescence (15.9\%). Weight change patterns during childhood and adolescence were marked by overall stability: $40.1 \%$ of participants were consistently normal, $15.6 \%$ underweight and $3.6 \%$ overweight/obese. Among those whose weight changed, $25.0 \%$ gained weight and $15.7 \%$ lost weight. In regression analyses, weight change categories based on self-reported weight statuses during childhood and adolescence were not associated with current metabolic syn-
\end{abstract}

drome risk factors after controlling for measured current BMI. Studies addressing the association between weight gains in early life with metabolic syndrome outcomes in early adulthood should not rely on recalled weight status during early life alone.

Keywords: Weight Change; Metabolic Syndrome; Metabolic Risk Factors' Mexican Young Adults

\section{INTRODUCTION}

Obesity and excessive weight gain in early life represent major risk factors for metabolic syndrome (MetS) in early adulthood [1-7]. In Mexico, as in other developing countries, the prevalence of MetS is increasing due to the rising prevalence of obesity [8,9]. Rates of MetS in Latin America now equal those in the developed world, increasing the burden of MetS-related diseases [10]. In 2006, prevalence of MetS in Mexico reached 22.2\% among men and $16.5 \%$ among women aged 25 to 34 years according to the National Cholesterol Education Program Adult Treatment Panel III (NCEP-ATP III) definition [11]. Although prevalence of MetS among Mexican young adults is lower in comparison with their older counterparts, it is likely to increase as they age. The early identification of metabolic risk related to weight gain and obesity represents an urgent strategy to prevent premature deaths and disability due to chronic diseases, as well as to reduce the economic burden [1, 12].

Given the association between excessive weight gain 
during childhood and adolescence on the risk of developing MetS, having a record of measured weight during childhood and adolescence might allow early identification of individuals at risk of metabolic abnormalities before the onset of chronic diseases. Some scholars have argued that past weight may even be more important for predicting chronic disease risk factors and development than current weight [13-15]. However, past records of weight status are not always available, particularly in developing countries where longitudinal records of weight are incomplete or inexistent due to the limited access to medical care and difficulties and costs associated with longitudinal data collection necessary to track weight change over time. Therefore, alternative options such as the use of self-reported retrospective information on weight status have been used in large scale studies. For instance, previous studies have assessed the accuracy of self-reported weight among Mexican Adolescents, and also self-reported body mass index (BMI) and body perception among Mexican adults; their findings suggested that self-reported weight among these populations are highly correlated with the measured BMI and thus may be valid to estimate weight in epidemiological studies $[16,17]$.

Although several studies have found self-reported data to be fairly accurate and useful for epidemiological purposes, other studies using self-reported weight status has shown controversial results. In a previous study, we found that most (63\%) college applicants in Mexico accurately reported their current weight status categories, with reporting accuracy lower among overweight and obese participants [18]. A review of the literature showed that for the most part, current weight tends to be underestimated and current height overestimated, with important differences between men and women [19]. However less is known about the validity and usefulness of recalled weight, height, body mass index (BMI) or weight status reports. Even less is known about their usefulness in screening patients for MetS risks.

Despite the several limitations with recalled weight status during childhood and adolescence, these may be the only information that could be easily available to assess weight change during childhood and adolescence in some countries. Understanding such limitations is important when trying to access the potential usefulness of self-reported weight status in early life among young adults. For instance, some limitations related to retrospective data collection on self-reported weight status is that participants may not recall past information correctly and responses may be influenced for desirability (response) bias [19]. However, other research has shown that the accuracy of the recalled weight status can be influenced by the elapsed time between the event and the data collection $[20,21]$. In fact, many studies have fo- cused on middle-aged or older adult populations with long recall periods (see Bayomi et al., 2008 for a review) [20]. It can be suggested that young adults may be more likely to recall accurately information as they elapse period is shorter. These studies have found that accuracy of recalled data is also influenced by many factors such as gender, race, current BMI and weight gain over the years [22]. There are very few studies focusing on younger adults and more recent recall periods. For example, Jenkins and colleagues developed an instrument to collect information on individuals aged 26 - 29 years old about their weight and height at ages 13 and 18 [13]. Results indicated that recalled weight and height used to calculate BMI underestimated their measured BMI values at those ages, suggesting an instrument with moderate sensitivity, but high specificity for obesity [13]. In general, previous studies examining recalled anthropometric measures have found that despite the limitations, recalled information may be useful; but its use requires some caution in the interpretation.

Given the high rates of obesity and MetS among Mexican young adults, and given the limited access to longitudinal data on their weight statues during childhood and adolescence is appropriate to explore the usefulness of recalled weight status to generate information about weight change at early ages in order to early identify people at risk of developing chronic diseases in late adulthood. Therefore, this study examined the association between retrospective self-reported weight change during childhood and adolescence, and current metabolic risk factors among Mexican young adults. In addition, we assessed whether these weight changes are associated with current metabolic risk factors independent of current BMI. This is because some of the effects of weight gain during early life on metabolic syndrome factors may be mediated through adult BMI [3]. In fact, weight and BMI during childhood are associated with young adult weight and BMI [4].

\section{MATERIAL AND METHODS}

\subsection{Participants}

We drew on data from a large-scale program of research being conducted in collaboration between the Universidad Autónoma de San Luis Potosí (UASLP) and the University of Illinois at Urbana-Champaign. All participants in this cross-sectional study were applicants to UASLP for the 2009 academic year. In 2009, 9981 individuals ages 16 to 54 applied to UASLP. These individuals were invited to participate in a health screen at the UASLP clinic. There were 9791 applicants who were screened by trained health care professionals at the UASLP clinic after an overnight fast. The health screening included anthropometric measurements and a blood 
draw. After that, participants were invited to complete a self-report questionnaire in Spanish about socioeconomic and health conditions. A total of 7434 individuals completed the questionnaire; out of those 5858 were aged 18 - 25. For this study, we selected the 4187 participants who were aged 18 - 25 who had complete information on anthropometric measurements - height, weight, BMI, waist circumference (WC), systolic blood pressure (SBP), and diastolic blood pressure (DBP) and fasting glucose (FG) - , self-reports of weight at childhood and adolescence, and sociodemographic controls. Funding limitations precluded lipids testing for all study respondents; therefore, a subset of 353 participants was randomly selected from the larger sample for high-density lipoprotein cholesterol (HDL-C) and triglycerides (TG) testing. Following procedures approved by Institutional Review Boards at both collaborating institutions, applicants who chose to allow their data to be used for research purposes provided written informed consent.

\subsection{Variables}

Sociodemographic information included age, gender, smoking, drinking, and income. Age was calculated using the date of birth and date of questionnaire completion. Gender was coded as $0=$ male and $1=$ female. Smoking categories were: never smoked, current smoker, and previous smoker. Drinking was coded as never, current drinker, previous drinker. Family monthly income was categorized as (in thousands of pesos): less than $\$ 10, \$ 10$ - $\$ 14, \$ 15$ - \$19, \$20 - \$24, \$25 - \$49, \$50 or more, or don't know.

Weight change categories were defined based on participants self-reported their weight status during childhood (5 to 10 years old) and adolescence. The response categories were: very low weight, low weight, average weight, overweight, or obese. Responses were recoded into three categories: underweight (very low and low), normal (average), and overweight/obese. Table 1 shows the six weight change categories which were defined from self-reported body weight statuses during childhood and adolescence: 1) consistently normal, the reference group, defined as self-reported normal weight during childhood and adolescence; 2) consistently underweight, defined as underweight during childhood and adolescence; 3 ) consistently overweight/obese, defined as overweight or obese during childhood and adolescence; 4) weight gain in early life, and 5) weight losses.

Anthropometric measurements included weight and height, and were measured with bare feet and light clothing. Weight was measured in the upright position to the nearest $0.1 \mathrm{~kg}$ using a calibrated scale (Torino, Tecno Lógica, Mexicana, Mexico). Height was measured using a fix stadiometer and recorded to the nearest $0.5 \mathrm{~cm}$. BMI was calculated as $\mathrm{kg} / \mathrm{m}^{2}$. WC was measured standing, immediately above the iliac crest and at the end of normal expiration, using a flexible, non-stretching nylon tape with accuracy to the nearest $0.1 \mathrm{~cm}$.

Blood pressure (BP) was measured according to a common protocol adapted from American Heart Association-recommended procedures. BP was taken on the dominant arm in the seated position using appropriately sized Welch Allyn cuffs.

Blood biomarkers included fasting blood glucose and lipids profile. Fasting blood glucose was determined according to the method of glucose oxidase peroxidase GOD-PAP (Alcyon 300 autoanalyzer from Abbott, reagents from Biosystems). A subsample of participants had serum lipid profiles carried out by an automatic analyzer for diagnostic use in vitro (Alcyon 300 autoanalyzer from Abbott, reagents from Biosystems). Results are expressed in $\mathrm{mg} / \mathrm{dl}$. Serum triglycerides were determined according to the glycerol phosphate oxidase peroxidase method, based on a colorimetric enzymatic reaction. HDL-C was determined by a direct method in which

Table 1. Definition of weight change patterns during childhood and adolescence.

\begin{tabular}{|c|c|c|c|}
\hline Weight change patterns & $\begin{array}{l}\text { Self-reported weight during } \\
\text { childhood }\end{array}$ & $\begin{array}{l}\text { Self-reported weight during } \\
\text { adolescence }\end{array}$ & Percentage in the dataset \\
\hline Consistently normal (CN) & Normal & Normal & $40.10 \%$ \\
\hline Consistently underweight (CUW) & Underweight & Underweight & $15.64 \%$ \\
\hline Consistently overweight/obese (COO) & Overweight/obese & Overweight/obese & $3.56 \%$ \\
\hline \multirow{2}{*}{ Weight gain in early ages (WG) } & Underweight & Overweight/obese & $2.94 \%$ \\
\hline & Normal & Overweight/obese & $9.43 \%$ \\
\hline \multirow[t]{2}{*}{ Weight losses (WL) } & Normal & Underweight & $9.17 \%$ \\
\hline & Overweight & Normal & $5.59 \%$ \\
\hline
\end{tabular}


a detergent solubilized the HDL-C, which was then quantified spectrophotometrically according to the cholesterol oxidase method.

Risk factors for MetS entitled elevated SPB and DBP, $\mathrm{WC}, \mathrm{FG}$, and TG, but reduced levels of HDL-C as defined by the ATP III criteria for MetS $[23,24]$.

\subsection{Statistical Analysis}

Data analysis was performed using STATA S.E. 12. All variables were assessed for normality, but results showed no relevant variations. Descriptive statistics were examined. Differences were assessed using Student's t-test for continuous variables. Regression analysis was used to assess the association between weight change categories as independent variable and each MetS risk factor as an individual outcome. Analyses were performed separately by gender. Model 1 included age, income levels, smoking, and drinking behaviors as controls. Model 2 included all variables from Model 1 and added current BMI.

\section{RESULTS}

\subsection{Descriptive Statistics}

Females represented $51.5 \%$ of the sample. The mean age was 19.0 years for males (95\% CI $18.4-19.1)$ and 18.8 for females (95\% CI 18.7 - 18.9). Although the difference was small, mean age was significantly different by gender $(p<0.001)$. Most participants $(58.7 \%)$ selfreported being normal weight during childhood, $31.2 \%$ underweight and $10.1 \%$ overweight or obese. At adolescence, $58.3 \%$ self-reported being of normal weight, $25.8 \%$ underweight and $15.9 \%$ overweight or obese. Turning to the description of weight change patterns during childhood and adolescence, $40.1 \%$ of the participants were consistently normal, $15.6 \%$ remained consistently underweight and $3.6 \%$ were consistently overweight/obese. Among those who changed weight, $25.0 \%$ had gained weight and $15.7 \%$ lost weight (Table 1).

The distribution of metabolic risk factors is displayed in Table 2 for descriptive purposes. All MetS risk factors were within normal levels, but the overall pattern shows that males tended to be at higher metabolic risk than females. As shown in Table 2, mean levels of SPB and DBP were higher for males than females $(p<0.001)$. Compared to females, males presented higher mean WC and FG, and TG $(p<0.001)$ and lower HDL-C $(p<$ 0.001) (Table 2).

\subsection{Associations between Self-Reported Weight Change and Current Metabolic Risk Factors}

Regression coefficients for the associations between
Table 2. Characteristics of MetS risk factors in Mexican young adults, $2009^{1}$.

\begin{tabular}{cccc}
\hline \multirow{2}{*}{$\begin{array}{c}\text { MetS risk } \\
\text { factors }\end{array}$} & Total & Males & Females \\
\cline { 2 - 4 } & $(\boldsymbol{n}=\mathbf{4 1 8 7})$ & $(\boldsymbol{n}=\mathbf{2 0 3 0})$ & $(\boldsymbol{n}=\mathbf{2 1 5 7})$ \\
\hline SBP (mmHg) & $109.8 \pm 10.5$ & $113.6 \pm 10.1$ & $106.2 \pm 9.7$ \\
DBP (mmHg) & $71.6 \pm 8.4$ & $73.9 \pm 8.1$ & $69.5 \pm 8.2$ \\
WC (cm) & $79.7 \pm 11.6$ & $82.5 \pm 11.6$ & $77.2 \pm 10.9$ \\
FG (mg/dl) & $84.8 \pm 7.7$ & $86.3 \pm 7.7$ & $83.5 \pm 7.4$ \\
& $(\boldsymbol{n}=\mathbf{3 5 3})$ & $(\boldsymbol{n}=\mathbf{1 4 3})$ & $(\boldsymbol{n}=\mathbf{2 1 0})$ \\
HDL-C (mg/dl) & $47.4 \pm 11.1$ & $45.8 \pm 11.1$ & $48.5 \pm 11.0$ \\
TG (mg/dl) & $107.9 \pm 50.8$ & $118.3 \pm 57.5$ & $100.8 \pm 44.4$ \\
\hline
\end{tabular}

${ }^{1}$ Mean $\pm \mathrm{SD}$; MetS $=$ metabolic syndrome, $\mathrm{SBP}=$ systolic blood pressure, $\mathrm{DBP}=$ diastolic blood pressure, $\mathrm{WC}=$ waist circumference, $\mathrm{FG}=$ fasting glucose, $\mathrm{HDL}-\mathrm{C}=$ high density lipoprotein cholesterol, $\mathrm{TG}=$ triglycerides .

weight change categories and MetS risk factors are displayed in Table 3. Results for Model 1 indicate that weight change patterns at younger ages were predictive of SBP, DBP and $\mathrm{WC}$ for males and females, but not FG, HDL or TG. However, almost all coefficients dropped to non-significance when current BMI was added in Model 2.

\section{DISCUSSION}

Longitudinal records of weight change are rare in developing countries primarily due to the lack of complete vital registration systems and limited access to stable medical care, which could allow for the collection of information at birth and during early stages in life [25, 26]. In addition, there are very few longitudinal studies in developing countries given the time commitment and high costs [26]. Therefore, we tested whether self-reported weight status categories during childhood and adolescence were useful in predicting metabolic risk factors among Mexican young adults. There is evidence of the validity of self-reported weight and body perception to estimate current weight in among Mexican adolescents and adults [16,17]. However, we found little evidence that weight change patterns based on recalled weight status during childhood and adolescence contributed to the prediction of metabolic risk at young adulthood. We further explored the predictive value of the recalled reports of body status at childhood and adolescence on metabolic risk factors when these measures were not combined into weight changes (data not shown). According to this analysis, after controlling for current BMI, weight statuses at childhood and adolescence did not have a significant effect on metabolic risk factors in this cohort $(p>0.05)$. Our findings indicate that the collection of measured current BMI in these contexts could 
Table 3. Regression coefficients assessing the association between weight change patterns and each individual component of the MetS in Mexican young adults, $2009^{1}$.

\begin{tabular}{|c|c|c|c|c|c|c|c|c|c|c|c|c|}
\hline \multirow{3}{*}{$\begin{array}{l}\text { MetS } \\
\text { risk } \\
\text { factors }\end{array}$} & \multicolumn{6}{|c|}{ Males } & \multicolumn{6}{|c|}{ Females } \\
\hline & \multicolumn{3}{|c|}{ Model 1} & \multicolumn{3}{|c|}{ Model 2} & \multicolumn{3}{|c|}{ Model 1} & \multicolumn{3}{|c|}{ Model 2} \\
\hline & Coef. & $95 \% \mathrm{CI}$ & & Coef. & $95 \% \mathrm{CI}$ & & Coef. & $95 \% \mathrm{CI}$ & & Coef. & $95 \% \mathrm{CI}$ & \\
\hline \multicolumn{13}{|c|}{ SBP (mmHg) } \\
\hline CUW & -1.46 & $(-2.70$ to -0.22$)$ & * & 0.43 & $(-0.79,1.64)$ & & -2.08 & $(-3.25$ to -0.92$)$ & $* * *$ & -0.20 & $(-1.30$ to 0.91$)$ & \\
\hline $\mathrm{COO}$ & 3.47 & (0.87 to 6.07$)$ & $* *$ & -0.71 & $(-3.05$ to 1.63$)$ & & 4.18 & $(1.36$ to 6.99$)$ & $* *$ & -0.01 & ( -2.49 to 2.47$)$ & \\
\hline WG & 2.43 & (1.24 to 3.63 ) & ${ }^{* * *}$ & -0.39 & $(-1.50$ to 0.73$)$ & & 1.94 & ( 0.90 to 2.98$)$ & *** & -0.08 & $(-1.09$ to 0.93$)$ & \\
\hline WL & -1.49 & $(-2.63$ to -0.35$)$ & $*$ & -0.79 & $(-1.86$ to 0.29$)$ & & -1.19 & $(-2.40$ to 0.02$)$ & & -0.08 & $(-1.27$ to 1.10$)$ & \\
\hline BMI & & & & 0.92 & (0.79 to 1.04$)$ & $* * *$ & & & & 0.84 & ( 0.73 to 0.95$)$ & $* * *$ \\
\hline$R^{2}$ & & & 4.0 & & & 17.0 & & & 3.0 & & & 16.0 \\
\hline \multicolumn{13}{|c|}{ DBP (mmHg) } \\
\hline CUW & -0.49 & $(-1.49$ to 0.50$)$ & & 0.85 & $(-0.13$ to 1.83$)$ & & -0.85 & $(-1.84$ to 0.13$)$ & & 0.48 & $(-0.50$ to 1.47$)$ & \\
\hline $\mathrm{COO}$ & 2.19 & $(0.33$ to 4.05$)$ & * & -0.79 & $(-2.56$ to 0.99$)$ & & 4.26 & (1.84 to 6.68$)$ & $* * *$ & 1.29 & $(-0.90$ to 3.48$)$ & \\
\hline WG & 1.90 & (0.95 to 2.84$)$ & $* * *$ & -0.11 & $(-1.01$ to 0.80$)$ & & 1.57 & ( 0.70 to 2.44$)$ & $* * *$ & 0.13 & $(-0.73$ to 0.99$)$ & \\
\hline WL & -0.24 & $(-1.22$ to 0.73$)$ & & 0.26 & $(-0.66$ to 1.19$)$ & & 0.02 & $(-1.03$ to 1.08$)$ & & 0.81 & $(-0.21$ to 1.83$)$ & \\
\hline BMI & & & & 0.65 & $(0.56$ to 0.74$)$ & $* * *$ & & & & 0.60 & (0.52 to 0.68$)$ & $* * *$ \\
\hline$R^{2}$ & & & 4.0 & & & 15.0 & & & 2.0 & & & 11.0 \\
\hline \multicolumn{13}{|c|}{$\mathrm{WC}(\mathrm{cm})$} \\
\hline CUW & -4.72 & $(-5.76$ to -3.69$)$ & $* * *$ & -0.15 & $(-0.92$ to 0.61$)$ & & -4.42 & $(-5.55$ to -3.30$)$ & $* * *$ & -0.15 & $(-0.87$ to 0.58$)$ & \\
\hline $\mathrm{COO}$ & 10.78 & (7.79 to 13.76 ) & *** & 0.67 & $(-0.66$ to 2.00$)$ & & 12.85 & (9.80 to 15.89 ) & $* * *$ & 3.36 & (1.65 to 5.07$)$ & $* * *$ \\
\hline WG & 7.06 & (5.70 to 8.43 ) & $* * *$ & 0.25 & $(-0.41$ to 0.91$)$ & & 4.87 & (3.70 to 6.04 ) & $* * *$ & 0.29 & $(-0.42$ to 0.99$)$ & \\
\hline WL & -0.88 & $(-2.17$ to 0.41$)$ & & 0.83 & (0.09 to 1.56$)$ & * & -2.62 & $(-3.84$ to -1.40$)$ & ${ }^{* * *}$ & -0.11 & $(-1.01$ to 0.79$)$ & \\
\hline BMI & & & & 2.22 & (2.12 to 2.31 ) & $* * *$ & & & & 1.91 & (1.81 to 2.01 ) & $* * *$ \\
\hline$R^{2}$ & & & 18.0 & & & 78.0 & & & 14.0 & & & 66.0 \\
\hline \multicolumn{13}{|c|}{$\mathrm{FG}(\mathrm{mg} / \mathrm{dl})$} \\
\hline CUW & -0.26 & $(-1.26$ to 0.75$)$ & & 0.13 & $(-0.89$ to 1.15$)$ & & -0.26 & $(-1.16$ to 0.63$)$ & & 0.17 & $(-0.74$ to 1.09$)$ & \\
\hline $\mathrm{COO}$ & -0.34 & $(-1.89$ to 1.21$)$ & & -1.20 & $(-2.78$ to 0.39$)$ & & -0.67 & $(-2.40$ to 1.07$)$ & & -1.64 & $(-3.37$ to 0.09$)$ & \\
\hline WG & 0.64 & $(-0.25$ to 1.53$)$ & & 0.07 & ( -0.89 to 1.02$)$ & & 0.38 & $(-0.46$ to 1.22$)$ & & -0.09 & $(-0.92$ to 0.74$)$ & \\
\hline WL & -0.46 & $(-1.37$ to 0.46$)$ & & -0.31 & $(-1.22$ to 0.60$)$ & & -0.29 & $(-1.17$ to 0.60$)$ & & -0.03 & $(-0.91$ to 0.85$)$ & \\
\hline BMI & & & & 0.19 & $(0.10$ to 0.28$)$ & $* * *$ & & & & 0.20 & (0.11 to 0.28$)$ & $* * *$ \\
\hline$R^{2}$ & & & 2.0 & & & 3.0 & & & 3.0 & & & 4.0 \\
\hline \multicolumn{13}{|c|}{ HDL (mg/dl) } \\
\hline CUW & 2.14 & $(-3.53$ to 7.82$)$ & & 1.7 & $(-3.98$ to 7.38$)$ & & -1.78 & $(-6.33$ to 2.77$)$ & & -2.72 & $(-7.20$ to 1.75$)$ & \\
\hline $\mathrm{COO}$ & 8.03 & $(-1.02$ to 17.08$)$ & & 8.8 & (0.43 to 17.16$)$ & * & 0.36 & $(-6.18$ to 6.90$)$ & & 3.52 & ( -2.81 to 9.84$)$ & \\
\hline WG & -4.06 & ( -8.91 to 0.79$)$ & & -2.76 & ( -8.03 to 2.51$)$ & & -1.5 & $(-5.20$ to 2.20$)$ & & -0.15 & $(-3.98$ to 3.68$)$ & \\
\hline WL & 3.08 & ( -3.45 to 9.61$)$ & & 3.08 & $(-3.42$ to 9.59$)$ & & 6.39 & $(-0.15$ to 12.93$)$ & & 5.62 & $(-0.91$ to 12.14$)$ & \\
\hline BMI & & & & -0.32 & $(-0.84$ to 0.20$)$ & & & & & -0.45 & $(-0.75$ to -0.16$)$ & $* *$ \\
\hline
\end{tabular}


Continued

\begin{tabular}{|c|c|c|c|c|c|c|c|c|c|c|c|c|}
\hline$R^{2}$ & & & 12.0 & & & 13.0 & & & 8.0 & & & 12.0 \\
\hline \multicolumn{13}{|c|}{$\mathrm{TG}(\mathrm{mg} / \mathrm{dl})$} \\
\hline CUW & -8.45 & ( -39.30 to 22.39$)$ & & -4.36 & $(-34.94$ to 26.22$)$ & & -6.33 & $(-29.14$ to 16.47$)$ & & -1.19 & $(-23.69$ to 21.31$)$ & \\
\hline $\mathrm{COO}$ & -24.4 & $(-53.71$ to 4.86$)$ & & -31.5 & ( -63.53 to 0.59$)$ & & 12.31 & $(-19.65$ to 44.26$)$ & & -4.88 & ( -39.37 to 29.61$)$ & \\
\hline WG & 21.56 & $(-2.29$ to 45.41$)$ & & 9.6 & $(-15.02$ to 34.23$)$ & & 2.22 & $(-12.00$ to 16.45$)$ & & -5.13 & $(-19.64$ to 9.37$)$ & \\
\hline WL & -24.3 & $(-47.81$ to -0.70$)$ & $*$ & -24.3 & $(-48.20$ to -0.31$)$ & * & -12.8 & ( -27.18 to 1.59$)$ & & -8.58 & $(-22.58$ to 5.43$)$ & \\
\hline BMI & & & & 2.93 & $(0.71$ to 5.14$)$ & $* *$ & & & & 2.48 & $(0.91$ to 4.05$)$ & $* *$ \\
\hline$R^{2}$ & & & 12.0 & & & 15.0 & & & 10.0 & & & 16.0 \\
\hline
\end{tabular}

${ }_{* * *}^{1}$ All analyses controlled for age, income levels, smoking, and drinking. ${ }^{2}$ Comparison with Consistently Normal category (reference group): ${ }^{*} p<0.05,{ }^{* *} p<0.01$, ${ }^{* * *} p<0.001$. MetS $=$ metabolic syndrome, $\mathrm{SBP}=$ systolic blood pressure, $\mathrm{CUW}=$ consistently underweight, $\mathrm{COO}=$ consistently overweight or obese, $\mathrm{WG}=$ weight gain, $\mathrm{WL}=$ weight loss, $\mathrm{BMI}=$ body mass index, $\mathrm{DBP}=$ diastolic blood pressure, $\mathrm{WC}=$ waist circumference, $\mathrm{FG}=$ fasting glucose, $\mathrm{HDL}=$ high density lipoprotein cholesterol, $\mathrm{TG}=$ triglycerides, Coef. $=$ regression coefficient, $95 \% \mathrm{CI}=95 \%$ confidence interval. $R^{2}=$ coefficient of determination.

be a better way to assess metabolic risk.

It is possible that young adults may not be completely able to recall their weight statuses even with a short recalled period. In our study, $10.1 \%$ of the participants reported being overweight or obese during childhood; however this percentage is lower than the $18.4 \%$ found for Mexican children ages 5 - 11 using data from 1999 National Health and Nutrition Survey (ENSANUT 1999) [27]. At adolescence, $15.9 \%$ of our participants reported being overweight or obese, but this percentage is also lower than the reports of $24.8 \%$ and $26.4 \%$ of excess weight for boys and girls, respectively, aged $10-17$ based on national estimates [28]. Some studies have found that recall is better for shorter periods of time (e.g. 10 years) [22], but it is possible that recall of anthropometric measurements for young ages may be problematic.

We used a self-reported measure of weight status to assess body size at younger ages. Previous studies have found moderate to low accuracy on reports of anthropometric measures for older populations even when different methodologies, such as body images, were used to collect the data $[20,29]$. A study comparing self-reports of weights and heights with the use of body silhouettes showed that body silhouettes were less precise for women [30]. Further studies should address whether other forms of measurement could yield measures that are more precisely capture body size and body weight changes at younger ages.

The findings need to be considered in light of several limitations. The main limitation is the lack of data to validate self-reports of weight status at younger ages. There is evidence that recalled weight status may underestimate the prevalence of obesity $[20,29]$, but we are not able to test this possibility in our sample, given the lack of past measured data. Second, even though the sample was diverse in terms of parental education and income, the respondents were college applicants in a single Mexican state and therefore findings may not generalize to all Mexican young adults. However, findings may be useful for targeted intervention among this specific population.

In conclusion, our study indicates that self-reported weight changes during childhood and adolescence are not predictive of metabolic risk beyond what can be obtained with measured current BMI. Future studies should examine whether other retrospective measures of selfreported weight status are better associated with current (and future) metabolic abnormalities, particularly in settings where longitudinal data on weight changes are limited.

\section{ACKNOWLEDGEMENTS}

Up Amigos acknowledges the contributions of research staff and study participants. Funding was provided by grants from the UASLP Hormones Laboratory at the School of Medicine, Clinical Biochemistry Laboratory at the Chemical Sciences School, and the University Health Center under agreement support C09-PIFI-030606 (to C. AradillasGarcia); the University of Illinois at Urbana-Champaign Research Board (\#09070) and Center on Health, Aging, and Disability (to F. Andrade); and the USDA National Institute of Food and Agriculture, Hatch Projects \#600108-793000-793323 (to M. Raffaelli) and \#600109-698000-698354 (to M. Terán-Garcia).

\section{REFERENCES}

[1] Rtveladze, K., Marsh, T., Barquera, S., Sanchez Romero, L.M., Levy, D., et al. (2013) Obesity prevalence in Mexico: Impact on health and economic burden. Public Health Nutrition, 1-7. http://dx.doi.org/10.1017/S1368980013000086

[2] Nadeau, K.J., Maahs, D.M., Daniels, S.R. and Eckel, R.H. (2011) Childhood obesity and cardiovascular disease: Links and prevention strategies. Nature Reviews Cardiology, 8, 513-258. http://dx.doi.org/10.1038/nrcardio.2011.86

[3] Slining, M.M., Kuzawa, C.W., Mayer-Davis, E.J. and 
Adair, L.S. (2011) Evaluating the indirect effect of infant weight velocity on insulin resistance in young adulthood: A birth cohort study from the Philippines. American Journal of Epidemiology, 173, 640-648. http://dx.doi.org/10.1093/aje/kwq435

[4] Sinaiko, A.R., Donahue, R.P., Jacobs, Jr. D.R. and Prineas, R.J. (1999) Relation of weight and rate of increase in weight during childhood and adolescence to body size, blood pressure, fasting insulin, and lipids in young adults: The Minneapolis Children's Blood Pressure Study. Circulation, 99, 1471-1476. http://dx.doi.org/10.1161/01.CIR.99.11.1471

[5] Fall, C.H., Sachdev, H.S., Osmond, C., Lakshmy, R., Biswas, S.D., Prabhakaran, D., et al. (2008) Adult metabolic syndrome and impaired glucose tolerance are associated with different patterns of BMI gain during infancy. Diabetes Care, 31, 2349-2356. http://dx.doi.org/10.2337/dc08-0911

[6] Hardy, R., Wadsworth, M.E.J., Langenberg, C. and Kuh, D. (2004) Birthweight, childhood growth, and blood pressure at 43 years in a British birth cohort. International Journal of Epidemiology, 33, 121-129. http://dx.doi.org/10.1093/ije/dyh027

[7] Hillier, T.A., Fagot-Campagna, A., Eschwège, E., Vol, S., Cailleau, M. and Balkau, B. (2006) Weight change and changes in the metabolic syndrome as the French population moves towards overweight: The DESIR Cohort. International Journal of Epidemiology, 35, 190-196. http://dx.doi.org/10.1093/ije/dyi281

[8] Misra, A. and Vikram, N.K. (2003) Clinical and pathophysiological consequences of abdominal adiposity and abdominal adipose tissue depots. Nutrition, 19, 457-466. http://dx.doi.org/10.1016/S0899-9007(02)01003-1

[9] Weiss, R., Dziura, J., Burgert, T.S., Tamborlane, W.V., Taksali, S.E., Yeckel, C.W., et al. (2004) Obesity and the metabolic syndrome in children and adolescents. The New England Journal of Medicine, 350, 2362-2374. http://dx.doi.org/10.1056/NEJMoa031049

[10] Cuevas, A., Alvarez, V. and Carrasco, F. (2011) Epidemic of metabolic syndrome in Latin America. Current Opinion in Endocrinology, Diabetes and Obesity, 18, 134138. http://dx.doi.org/10.1097/MED.0b013e3283449167

[11] Escobedo, J., Schargrodsky, H., Champagne, B., Silva, H., Boissonnet, C.P., Vinueza, R., et al. (2009) Prevalence of the metabolic syndrome in Latin America and its association with sub-clinical carotid atherosclerosis: The CARMELA cross sectional study. Cardiovascular Diabetology, 8, 52. http://dx.doi.org/10.1186/1475-2840-8-52

[12] WHO (2011) Noncommunicable diseases country profiles 2011. World Health Organization, Geneva.

[13] Jenkins, T.M., Buncher, C.R., Akers, R., Daniels, S.R., Lawson, M.L., Khoury, P.R., et al. (2013) Validation of a weight history questionnaire to identify adolescent obesity. Obesity Surgery, 23, 1404-1412.

http://dx.doi.org/10.1007/s11695-013-0901-7

[14] Lissner, L., Odell, P.M., D’Agostino, R.B., Stokes, J., Kreger, B.E., Belanger, A.J., et al. (1991) Variability of body weight and health outcomes in the Framingham population. The New England Journal of Medicine, 32,
1839-1844.

http://dx.doi.org/10.1056/NEJM199106273242602

[15] Hamm, P., Shekelle, R.B. and Stamler, J. (1989) Large fluctuations in body weight during young adulthood and twenty-five-year risk of coronary death in men. American Journal of Epidemiology, 129, 312-318.

[16] Davis, H. and Gergen, P.J. (1994) The weights and heights of Mexican-American adolescents: The accuracy of self-reports. American Journal of Public Health, 84, 459-462. http://dx.doi.org/10.2105/AJPH.84.3.459

[17] Osuna-Ramírez, I., Hernández-Prado, B., Campuzano, J.C. and Salmerón, J. (2006) Body mass index and body image perception in Mexican adult population: The accuracy of self-reporting. Índice de masa corporal y percepción de la imagen corporal en una población adulta Mexicana: La precisión del autorreporte. Salud Pública de México, 48, 94-103.

http://dx.doi.org/10.1590/S0036-36342006000200003

[18] Andrade, F.C.D., Raffaelli, M., Teran-Garcia, M., Jerman, J.A. and Aradillas-Garcia, C. (2012) Weight status misperception among Mexican young adults. Body Image, $\mathbf{9}$, 184-188. http://dx.doi.org/10.1016/j.bodyim.2011.10.006

[19] Gorber, S.C., Tremblay, M, Moher, D and Gorber, B. (2007) A comparison of direct vs. self-report measures for assessing height, weight and body mass index: A systematic review. Obesity Reviews, 38, 307-326. http://dx.doi.org/10.1111/j.1467-789X.2007.00347.x

[20] Bayomi, D.J. and Tate, R.B. (2008) Ability and accuracy of long-term weight recall by elderly males: The Manitoba Follow-up Study. Annals of Epidemiology, 18, 36-42. http://dx.doi.org/10.1016/j.annepidem.2007.06.009

[21] Tamakoshi, K., Yatsuya, H., Kondo, T., Hirano, T., Hori, Y., Yoshida, T., et al. (2003) The accuracy of long-term recall of past body weight in Japanese adult men. International Journal of Obesity and Related Metabolic Disorders, 27, 247-252. http://dx.doi.org/10.1038/sj.ijo.802195

[22] Perry, G.S., Byers, T.E., Mokdad, A.H., Serdula, M.K. and Williamson, D.F. (1995) The validity of self-reports of past body weights by U.S. adults. Epidemiology, 6, 6166.

http://dx.doi.org/10.1097/00001648-199501000-00012

[23] Grundy, S.M., Brewer Jr, H.B., Cleeman, J.I., Smith Jr, S.C. and Lenfant, C. (2004) Definition of metabolic syndrome: Report of the National Heart, Lung, and Blood Institute/American Heart Association conference on scientific issues related to definition. Circulation, 109, 433438. http://dx.doi.org/10.1161/01.CIR.0000111245.75752.C6

[24] Alberti, K.G.M.M., Eckel, R.H., Grundy, S.M., Zimmet, P.Z., Cleeman, J.I. and Donato, K.A. (2009) Harmonizing the metabolic syndrome. Circulation, 120, 1640-1645. http://dx.doi.org/10.1161/CIRCULATIONAHA.109.1926 $\underline{44}$

[25] Peters, D.H., Garg, A., Bloom, G., Walker, D.G., Brieger, W.R. and Hafizur Rahman, M. (2008) Poverty and access to health care in developing countries. Annals of the New York Academy of Sciences, 1136, 161-171. http://dx.doi.org/10.1196/annals.1425.011

[26] Durrant, V.L. and Menken, J. (2002) Leveraging Longi- 
tudinal Data in Developing Countries: Report of a Workshop. The National Academies Press, Washington, DC.

[27] Bonvecchio, A., Safdie, M., Monterrubio, E.A., Gust, T., Villalpando, S. and Rivera, J.A. (2009) Overweight and obesity trends in Mexican children 2 to 18 years of age from 1988 to 2006 . Tendencias de sobrepeso y obesidad en niños Mexicanos de 2 a 18 años de edad: 1988 a 2006. Salud Pública de México, 51, S586-S594. http://dx.doi.org/10.1590/S0036-36342009001000013

[28] Del Río-Navarro, B.E., Velázquez-Monroy, O., SánchezCastillo, C.P., Lara-Esqueda, A., Berber, A., Fanghänel, G., et al. (2004) The high prevalence of overweight and obesity in Mexican children. Obesity Research, 12, 215 223. http://dx.doi.org/10.1038/oby.2004.28

[29] Must, A., Willett, W.C. and Dietz, W.H. (1993) Remote recall of childhood height, weight, and body build by elderly subjects. American Journal of Epidemiology, 138, 56-64.

[30] Koprowski, C., Coates, R.J. and Bernstein, L. (2001) Ability of young women to recall past body size and age at menarche. Obesity Research, 9, 478-485. http://dx.doi.org/10.1038/oby.2001.62 